\title{
NUNCA MAIS O SILÊNCIO POR UMA POLIITICA DAS MEMÓRIAS DO FEMININO NA RESISTÊNCIA
}

\author{
Judite Primo' \\ Vânia Brayner ${ }^{2}$
}

\section{Resumo}

A frase «nunca mais o silêncio» é sobre memória, verdade e justiça para as vítimas do totalitarismo, mas com ela queremos falar sobre o apagar das memórias das mulheres na História, apesar de muitas delas não terem silenciado ante a repressão. Com esta frase, também reafirmamos a ebulição dos movimentos sociais feministas contemporâneos, cujo amplo conjunto de pautas evidencia o amadurecimento e os avanços das suas lutas globais. Este artigo reitera as mulheres como produtoras de uma história transformadora e, sobretudo, lança uma questão fundamental à museologia contemporânea: o que temos feito para pesquisar, registrar e difundir essas histórias?

\section{Palavras-chave}

silêncio, memória, resistência, feminino, museologia

\begin{abstract}
The phrase "silence never again" is about memory, truth and justice for the victims of totalitarianism, but with it we want to discuss the erasing of women's memories in history, although many of them had not silenced in the face of repression. With this phrase, we also restate the ebullition of contemporary feminist social movements, whose broad set of guidelines highlights the maturation and advancement of their global struggles. This article reaffirms women as producers of a transformative history and, above all, launches a fundamental question to contemporary museology: what have we done to research, record and disseminate these stories?
\end{abstract}

\section{Key words}

silence, memory, resistance, female, museology

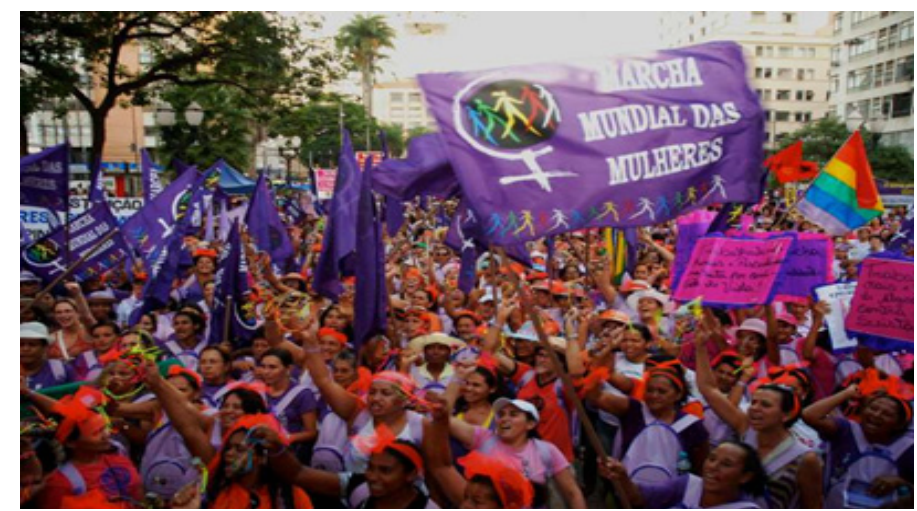

$3^{a}$ Ação Internacional da Marcha Mundial das Mulheres. De 8 a 18 de março de 2010, três mil mulheres marcharam 120 km entre as cidades de Campinas e São Paulo, a gritar:"seguiremos em Marcha até que todas sejamos livres!"

Foto: João Zinclar/MMM-Brasil

\footnotetext{
I Museóloga e Professora Doutora em Educação, diretora do Departamento de Museologia da Universidade Lusófona de Humanidade e Tecnologia - ULHT, em Lisboa, Portugal.

2 Doutoranda em Museologia pela Universidade Lusófona de Humanidades e Tecnologia - ULHT, em Lisboa, Portugal. Bolsista Capes de Doutorado Pleno no Exterior - Processo BEX 2302/I5-2.Antropóloga, jornalista e fotógrafa, especialista em Economia da Cultura.
} 


\section{Introdução}

As memórias do feminino na vida social e política nunca estiveram tão em evidência como no mundo contemporâneo, num incessante movimento para fazê-las emergir não mais como memórias coadjuvantes dos feitos de "grandes homens», mas como protagonistas das suas próprias histórias e das grandes transformações sociais, políticas e culturais no mundo. Esse movimento pelo desarquivamento da dimensão coletiva da memória do feminino, iniciado a partir da década de 1970, traz grandes novidades aos museus e lugares de memórias do mundo ocidental e põe em cheque toda uma história de silenciamentos nesses espaços, ainda bastante carente de investigações científicas. Este silenciamento se dá, segundo a professora emérita da Universidade de Paris VII, Michelle Perrot, porque a História sempre privilegiou a cena pública - a política, a guerra - onde as mulheres pouco apareciam (o que não significa que não atuavam) e cuja narrativa tradicional sempre reservou às mulheres o papel de figurantes: "no teatro da memória, as mulheres são sombras tênues" (Perrot, 1989: 9-18). Neste seu artigo Práticas da Memória Feminina, Perrot diz que a memória das mulheres, assim como sua escrita, foi relevada a uma memória familiar, semi-oficial, uma memória do privado, na qual inclui-se o culto aos mortos, em sua maioria aos heróicos homens que tombaram nas guerras, nas revoltas e revoluções.

Sabemos que a fala das mulheres na esfera produtiva, nos espaços públicos e de poder foi silenciada desde tempos imemoriais. Até então, esses eram locus substantivamente masculinos. Em As mulheres ou os silêncios da história (2005), Perrot diz que a fala e a presença femininas irromperam na história como uma inovação do século 19, pois antes disso o passado das mulheres era "um oceano de silêncio" (Perrot, 2005: 9). Um mar de águas silentes, no qual o navio da história zarpou e «esqueceu» as mulheres no obscuro porto da espera reprodutiva, da vida doméstica, acrônicas, alheias aos acontecimentos sociais, sem reconhecerem-se produtoras da vida social.

\footnotetext{
No início era o Verbo, mas o Verbo era Deus, e Homem. O silêncio é o comum das mulheres. Ele convém à sua posição secundária e subordinada. [...] O silêncio é um mandamento reiterado através dos séculos pelas religiões, pelos sistemas políticos e pelos manuais de comportamento. (Perrot, 2005: 9)
}

No Brasil, o silêncio sobre as atrocidades da ditadura militar, em um passado breve, perdura até os dias atuais. Pouco ou quase nada foi feito para recuperar essas memórias, conhecer a verdade e fazer justiça para os homens e mulheres que desapareceram ou foram brutalmente assassinad@s ${ }^{3}$ por combaterem o regime militar. $O$ pouco do que já foi feito para romper esse silêncio do Estado brasileiro em relação aos crimes contra os direitos humanos praticados por agentes estatais da repressão, ainda é limitado à busca pela memória e pela verdade histórica, pois justiça ainda constitui-se numa utopia. Mas esse silêncio é ainda mais ensurdecedor quando reporta-se às memórias e à história

3 Ao seguirmos a ideia da museóloga Aída Rechena de que "não podemos continuar a utilizar uma definição de pessoa que seja generalista" e que "devemos procurar evitar cair na armadilha do falso neutro" (RECHENA, 20II: I6I), definimos por utilizar, sempre que necessário, o símbolo@ para incluir as mulheres em nosso discurso. 
produzidas por mulheres que participaram ativamente das lutas do movimento estudantil, partidos políticos, sindicatos e organizações clandestinas, a desafiar uma sociedade patriarcal que impunha às mulheres o passivo papel doméstico e reprodutor.

Segundo o site do Instituto Vladimir Herzog, intitulado Memórias da Ditadura ${ }^{4}$, mesmo entre os «companheiros de luta» a importância da participação dessas mulheres era minimizada. Por isso, na «divisão sexual» das tarefas revolucionárias, poucas mulheres chegaram a ser dirigentes dessas organizações, mas não raro elas encarregavam-se das ações mais perigosas, exatamente porque despertavam menor interesse das forças repressoras.

Muitas tiveram papel de destaque em combates armados contra as forças de segurança do regime. Das mulheres que participaram da guerrilha urbana, cerca de 45 foram mortas ou estão desaparecidas até os dias atuais. Quando não eram guerrilheiras, as mulheres atuavam como enfermeiras e professoras, como na Guerrilha do Araguaia, em que foram o primeiro elo de integração com a população camponesa local. (Memórias da Ditadura, s/d)

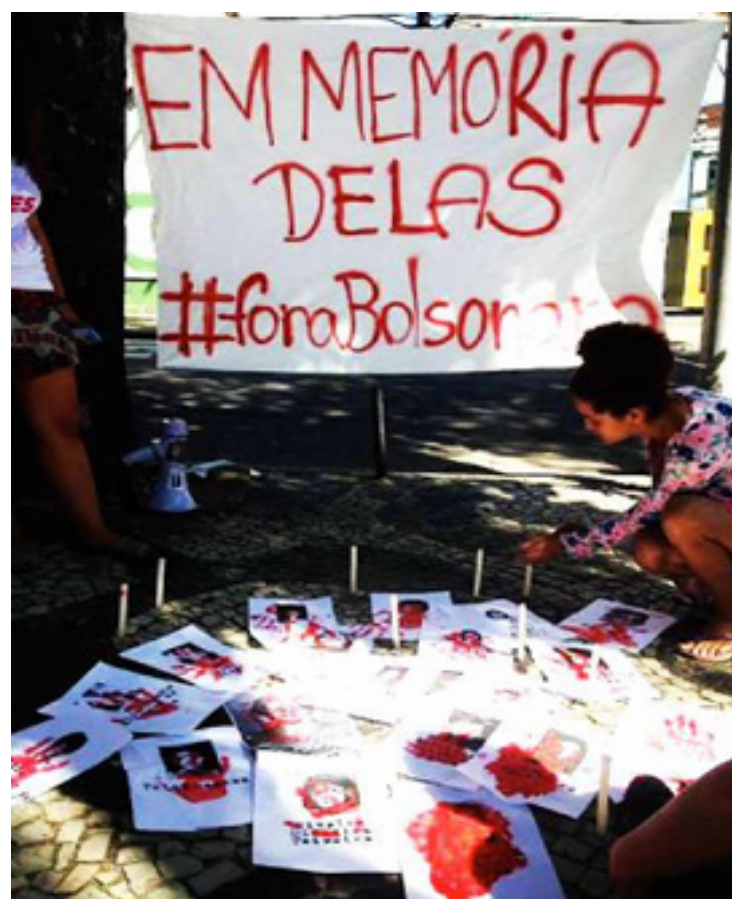

Foto: MMM/Brasil - maio/2016

Ao atuarem como elos entre a clandestinidade e o mundo exterior, essas mulheres expunham-se sobremaneira e ao caírem nas mãos das forças da repressão, eram recolocadas em seu «devido lugar»: adjetivos como vagabundas e prostitutas eram usuais, além de serem obrigadas a despirem-se "em frente aos agentes da ditadura, sempre do sexo masculino" (Memórias da Ditadura, s/d). Mesmo submetidas igualmente às torturas físicas e psicólogicas impostas aos homens capturados, ainda eram expostas a todo tipo de violência sexual, a abortos forçados, a sessões de torturas na frente de filh@s e até a assistirem à tortura das suas crianças. Estamos a falar do Brasil, no entanto, em vários lugares

4 Para saber mais sobre as memórias da atuação das mulheres durante a ditadura militar no Brasil, ver em: http://memoriasdaditadura.org.br/mulheres/index.html 
Nunca mais o silêncio

Por uma política das memórias do feminino na resistência

do mundo e em diversos períodos históricos, as mulheres sempre arriscaram-se ao atuar na política e nos movimentos sociais, ao participar de lutas armadas, ao ocupar espaços quase sempre hostis à presença feminina.

Em seus estudos da História, sob a perspectiva do feminino, Perrot preocupou-se em decifrar o papel das mulheres nos acontecimentos públicos, na resistência, na "ação das mulheres dissimulada na trama do cotidiano" (Perrot, 1989: 42). Ela nos diz que esse movimento da nova história é relativamente recente, iniciado por volta dos anos 1970, quando o feminismo assumiu papel ativo no desvelamento das histórias de vida das mulheres anônimas, ignoradas até então. Essa incesssante busca pelas memórias do feminino na cena pública - pois «a história das mulheres», como diz Perrot, não se atém a biografias específicas, mas ao sentido coletivo do termo - reuniu dados com testemunhos escritos e orais, instituiu lugares de memória e tornou visível o «eu» das mulheres na vida social, o qual "toda uma educação inculcou o decoro do esquecimento de si” (Perrot, 1989:17). De lá pra cá, gerações de historiadoras e intelectuais de diversas áreas produziram inúmeras investigações científicas, teses, livros, artigos e estudos no campo acadêmico de diversos países europeus, da Índia e Japão, e das américas do Norte e Latina (especialmente o Brasil, como ressalta Perrot). Um movimento mundial da história das mulheres, cujo desenvolvimento acompanhou na surdina a luta pela emancipação e libertação das mulheres.

\footnotetext{
A história das mulheres mudou. Em seus objetos, em seus pontos de vista. Partiu de uma história do corpo e dos papéis desempenhados na vida privada, para chegar a uma história das mulheres no espaço público da cidade, do trabalho, da política, da guerra, da criação. Partiu de uma história das mulheres vítimas para chegar a uma história das mulheres ativas, nas múltiplas interações que provocam a mudança. (Perrot, 2007: I5-16)
}

No presente, as herdeiras das feministas que lutaram pelo voto, pelo acesso à educação, por melhores condições de vida e trabalho, pela liberação sexual, continuaram a fazer história e hoje tomam as ruas em marchas de resistências que constituem-se em instrumentos políticos de luta coletiva, a impulsionar movimentos de massa com um amplo conjunto de pautas que evidencia o amadurecimento e os avanços nas discussões das lutas feministas no mundo. Para além das lutas específicas, esses movimentos de mulheres constituem-se em ativismos políticos que se contrapõem à ideologia neoliberal, patriarcal, racista, homofóbica e destruidora do meio ambiente, como apregoa a Marcha Mundial das Mulheres - MMM, inspirada nas 850 mulheres canadenses que marcharam 200 quilômetros em Quebec, no ano de 1995, a exigir de forma simbólica «Pão e Rosas», numa ação que "marcou a retomada das mobilizações das mulheres nas ruas, fazendo uma crítica contundente ao sistema capitalista como um todo"5, cujas conquistas significativas fomentaram novos movimentos. Mas igualmente não podemos esquecer o legado histórico deixado por outras mulheres que marcharam pela igualdade de direitos e por justiça - como em Nova lorque (1968), em Londres (1969 e 197I), na Argentina (198I) e em tantos outros lugares do mundo.

5 Site da Marcha Mundial das Mulheres (MMM), ver mais em: https://marchamulheres.wordpress.com/mmm/ 
No entanto, as ações de maior impacto que vêm conquistando um caráter global para os movimentos sociais feministas se deram a partir do ano 2000, com a Marcha Mundial das Mulheres, cujo lema inicial era «2000 razões para marchar contra a pobreza e a violência sexista».A MMM realiza ações massivas a cada cinco anos, que impactaram os movimentos sociais de mulheres no mundo de 2000 a 2015. Em 2000, a primeira Marcha teve a participação de mais de 5.000 grupos de mulheres em 159 países e territórios. No seu encerramento, um documento com 17 pontos de reivindicações e cinco milhões de assinaturas foi entregue à Organização das Nações Unidas (ONU), em Nova lorque; aos responsáveis do Fundo Monetário Internacional e ao Banco Mundial. Mais uma vez, o silêncio foi a resposta desses organismos transnacionais.

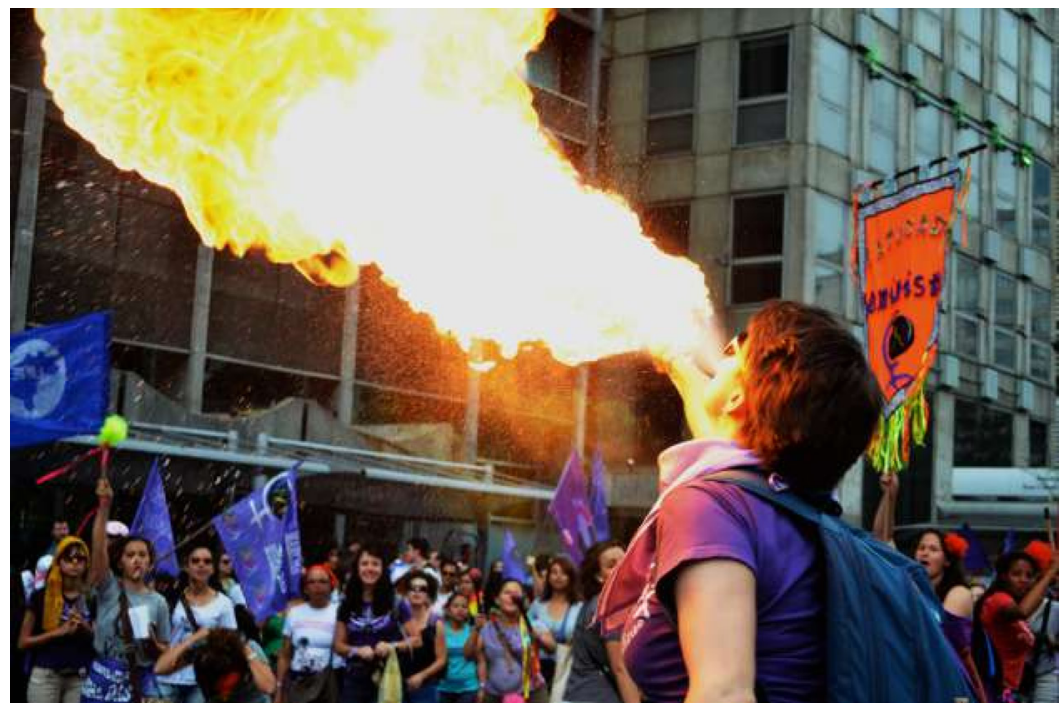

Marcha de encerramento do $9^{\circ}$ Encontro Internacional da MMM, agosto de 20I3, São Paulo. Foto: Cíntia Barenho/MMM/Brasil

\section{Margaridas do Brasil — memória viva em marcha rumo ao futuro}

Igualmente influenciado pelos resultados positivos da Marcha Pão e Rosas de Quebec, um dos primeiros movimentos sociais brasileiros a unir-se à ideia da MMM foi o das trabalhadoras rurais, cujas lutas no campo eram organizadas desde a década de 1980. A Marcha das Margaridas - MM é coordenada pela Confederação Nacional dos Trabalhadores na Agricultura - CONTAG, por 27 federações e 4 mil sindicatos de trabalhadores e trabalhadoras na agricultura, além de organizações parceiras dos movimentos feministas e demais mulheres trabalhadoras, centrais sindicais e organizações internacionais.

A MM acontece em Brasília (DF), sempre no dia 12 de agosto, data da morte da trabalhadora rural e líder sindicalista Margarida Maria Alves, assassinada por latifundiários em 1983, na Paraíba. Desde a primeira marcha, realizada no ano 2000 , até $2015^{6}$, cerca de 350.000 mulheres do campo, da floresta e das águas marcharam "Contra a Fome, a Pobreza e a Violência Sexista» e por «Desenvolvimento Sustentável com Democracia, Justiça, Autonomia, Igualdade e Liberdade», lema da última Marcha realizada.Ao analisarmos os temas das mar chas já ocorridas, percebemos os avanços incorporados ao movimento - das 
Nunca mais o silêncio

Por uma política das memórias do feminino na resistência

demandas específicas, comuns à realidade dessas mulheres, aos objetivos políticos e sociais globais, presentes em diversos movimentos sociais locais, nacionais e internacionais, que buscam transformar o sistema econômico e político que hoje norteia as relações dos seres humanos entre si e com a Natureza.

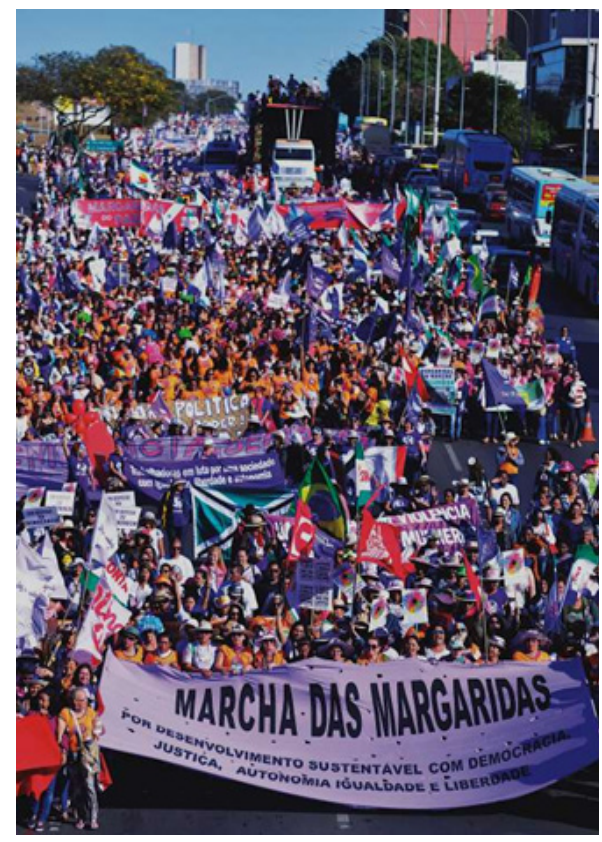

Marcha das Margaridas, Brasília, 2015. Foto: Luiz Fernandes/Contag

Em 20I5, a ONU Mulheres Brasil ressaltou a importância do movimento para a promoção da autonomia, participação e capacidade política das mulheres e para a sustentabilidade da vida humana em sintonia com a preservação e a gestão racional dos recursos naturais do planeta e, por isso, foi uma das instituições apoiadoras da Marcha na participação de delegações de mulheres de 15 países da América Latina e da África. Não à toa, o Observatório da Marcha das Margaridas ${ }^{7}$ busca ser um "Transformatório», a acompanhar a transmutação de um movimento dinâmico, em processo contínuo de construção e reconstrução da sua capacidade de mobilização e da qualidade de sua inserção política, em favor do empoderamento das mulheres e das mudanças efetivas nas principais questões que aflingem a Humanidade e o Planeta:

é uma transformação que revela um projeto de sociedade, uma visão de mundo pelas lentes do feminismo e que afirma insistentemente a necessidade da justiça, da soberania dos povos e das mulheres, da igualdade e da liberdade para todas/os. (Transformatório -MM, s/d)

Segundo a cientista política Flávia Biroli (2015), para as margaridas o direito ao trabalho, o direito ao próprio corpo e a reestruturação dos âmbitos produtivo e reprodutivo da vida estão imperiosamente conectados 8 . "Trata-se de democratizar o Brasil, tarefa na qual as mulheres têm muito a contribuir, a partir dos horizontes utópicos do feminismo e da política" (Contag, 20 I5: 78), que são incompatíveis com o agronegócio e seus agrotóxicos e alimentos

7 Site que reúne materiais relacionados à Marcha das Margaridas, desde a sua primeira edição, incluindo material gráfico, fotográfico e audiovisual. Também hospeda trabalhos acadêmicos e matérias jornalísticas sobre a Marcha e as bandeiras de luta das mulheres rurais, além de links das entidades parceira.Ver em: http://transformatoriomargaridas.org.br

8 Ver mais em: Biroli, Flávia e Miguel, Luis Felipe. Feminismo e política: uma introdução. São Paulo: Ed. Boitempo, 20I4. 
transgênicos; com a mercantilização da Natureza, em especial a privatização dos recursos hídricos e da biodiversidade planetária; com a discriminação e violência sexista, homofóbica e lesbofóbica; com o racismo e a xenofobia; e com a incessante reprodução das desigualdades na dinâmica capitalista que promove a pobreza e a exclusão social, cultural e política.

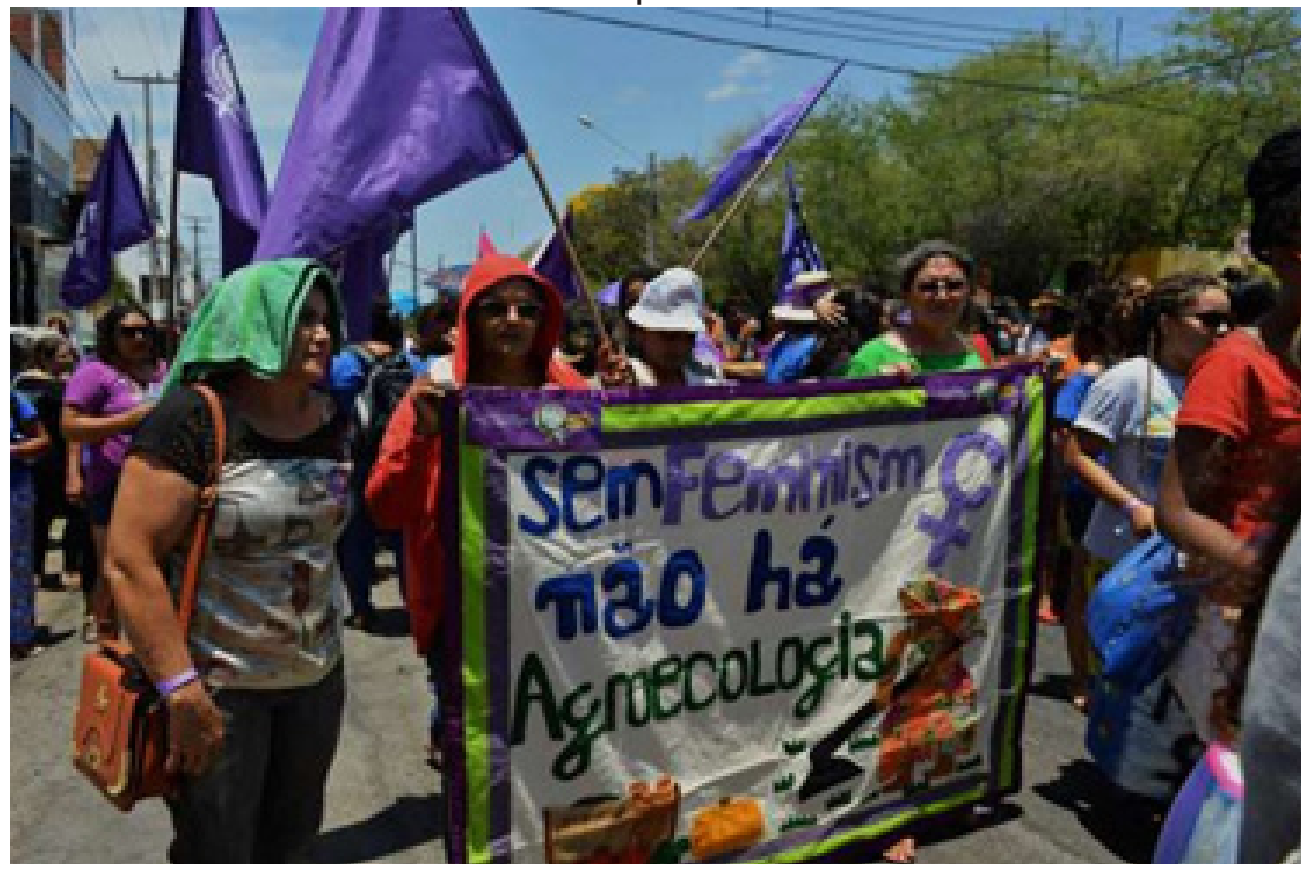

Encerramento da $4^{\text {a }}$ Ação Internacional da MMM, Mossoró, Rio Grande do Norte, outobro de 2015. Foto: MMM/Brasil

\section{Mulheres em Marcha - Ações para mudar o mundo}

O alcance e a repercussão política da primeira Marcha Mundial das Mulheres - MMM, no ano 2000, deu início a um movimento internacional inédito e, assim, a uma nova «história das mulheres» que, como deseja Perrot, começou a ser criada de forma coletiva. Mesmo num cenário adverso, a MMM conseguiu tornar-se um movimento permanente, autônomo, auto-gestionado e articulado com outras organizações e movimentos sociais:

As mulheres propuseram ir além do possível e ousaram seguir atuando juntas para construir a MMM como um movimento permanente, uma consequência das novas forças e sinergias mobilizadas em cada local. (MMM, s/d)

As marchas acontecem a cada cinco anos e suas Ações Internacionais constituem-se em instrumentos de mobilização e de construção de suas plataformas e estratégias políticas, com ações preparatórias em nível local, nacional e internacional - seminários, encontros, reuniões e atividades diversas - que culminam com a realização das marchas. Esta forma de atuação permitiu à MMM consolidar um feminismo não institucionalizado e militante, que recusa a fragmentação de agendas e articula todas as dimensões das lutas contra o sistema capitalista - de classe, gênero e raça.

A luta para mudar o mundo e mudar a vida das mulheres se dá como parte de um só movimento. Não basta identificar que os impactos deste sistema 
são piores para as mulheres. Partimos de uma análise de que o capitalismo faz uso de estruturas patriarcais no seu processo de acumulação. Não buscamos apenas diminuir impactos negativos deste modelo na vida das mulheres, mas sim organizamos uma luta para transformar as estruturas que organizam todas as relações de desigualdade e poder. (MMM, s/d)

Dessa forma, a MMM voltou às ruas em 2005, para realizar sua 2a Ação Internacional iniciada no dia 8 de março, em São Paulo, e lançar a elaboração da Carta Mundial das Mulheres para a Humanidade com o objetivo de expressar "alternativas econômicas, sociais e culturais para a construção de um mundo fundado nos princípios da igualdade, liberdade, justiça, paz e solidariedade entre os povos e seres humanos em geral, respeitando o meio ambiente e a biodiversidade" . A Carta foi representada simbolicamente pela grande Colcha Mosaico Mundial de Solidariedade, bordada com retalhos durante sete meses, a partir da contribuição de cada país por onde ela passava.

Como a estratégia de seguir uma plataforma consensual de pautas não impede que lutas emergentes, de acordo com as realidades de cada país ou grupos de mulheres, sejam utilizadas como eixos de trabalho, o lema Seguiremos em marcha até que todas sejamos livres é suficientemente amplo para abraçar diversas causas. No Brasil, em 20I4, foi criado um mapa das resistências e alternativas, construído de forma coletiva para destacar a trajetória da Ação no Brasil, suas reivindicações e articulações. O mapa seguiu para o Peru, onde delegadas de 10 países das Américas, África, Ásia, Europa e do Mundo Árabe participaram do $4^{\mathrm{a}}$ Encontro Regional da Marcha Mundial das Mulheres nas Américas, em apoio à luta das mulheres peruanas contra empresas mineradoras que exploram e invadem suas terras e suas comunidades.

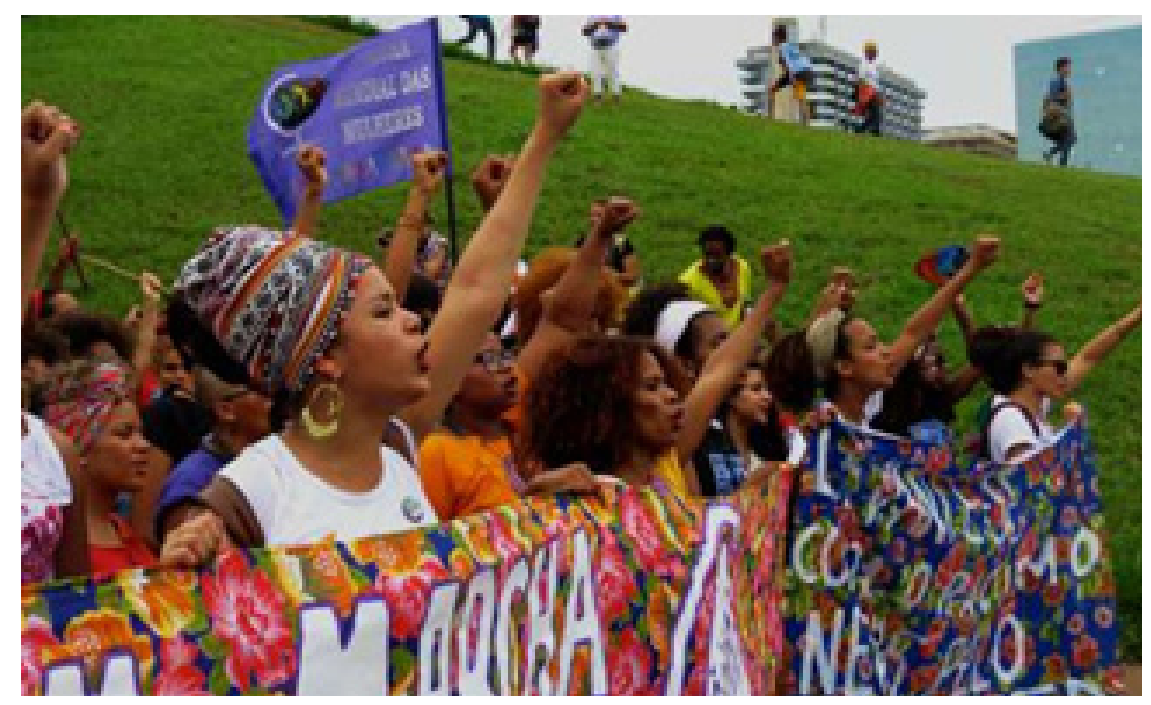

Marcha das Mulheres Negras contra o Racismo, a Violência e pelo Bem Viver, novembro de 20I5, Brasília (DF)

Foto:Ana Carolina Barros, MMM/Brasil - outubro/20I5

Em 2017, destaca-se a Women's March on Washington (Marcha das MuIheres em Washington), organizada como protesto à eleição do presidente ame-

9 Ver mais em: Carta Mundial das Mulheres para a Humanidade, publicada em http://cartamundialdasmulheres.blogspot.pt, em 24/06/2009. Acessada em: 25/ I I/20I 7 
ricano Donald Trump, declaradamente racista, xenófobo, misógino e machista. $A$ Marcha desdobrou-se nas sister marches (marchas irmãs) em diversas cidades do mundo e contabilizou cerca de dois milhões de pessoas nos EUA e cinco milhões de pessoas no mundo, num total de 914 marchas (sendo 653 nos EUA). Um dos motes do movimento foi direitos das mulheres são direitos humanos e direitos humanos são direitos das mulheres, o que possibilitou a diversidade de pautas presentes na Marcha, representada no discurso proferido pela filósofa e ativista Angela Davis:

Nós representamos forças poderosas de mudança que estão determinadas a impedir as culturas moribundas do racismo e do hetero-patriarcado de levantar-se novamente. [...] A luta para salvar o planeta, interromper as mudanças climáticas, para garantir acesso a água das terras do Standing Rock Sioux, à Flint, Michigan, a Cisjordânia e Gaza.A luta para salvar nossa flora e fauna, para salvar o ar - este é o ponto zero da luta por justiça social. Esta é uma Marcha das Mulheres e ela representa a promessa de um feminismo contra o pernicioso poder da violência do Estado. E um feminismo inclusivo e interseccional que convoca todos nós a resistência contra o racismo, a islamofobia, ao anti-semitismo, a misoginia e a exploração capitalista (Davis, 2017).

Um forte discurso que alastrou-se mundo a fora como rastro de pólvora, a proclamar a resistência contra o poder da violência do Estado. Davis é uma das principais formuladoras da ideia de que o capitalismo e o sexismo apresentam-se na sociedade contemporânea como condições estruturantes nas relações humanas que, combinadas, geram a opressão.

\section{E a museologia com isso?}

Como já discutimos anteriormente, o discurso de que mulheres não fazem história porque estão fora da cena pública, hoje já não tem mais qualquer aderência à realidade cotidiana, concreta, visível. Com um lenço branco na cabeça e um cartaz pendurado no pescoço com a inscrição son 30.000, a jornalista e escritora Vera Vigevani de Jarach, 89 anos, uma das Mães da Plaza de Mayo, resumiu numa frase a luta de cerca de 400 mulheres argentinas: «nunca mais o silêncio», ao dirigir-se à Angela Merkel em maio de 2017, quando a chanceler alemã visitava o Parque da Memória - Monumento às Vítimas do Terrorismo de Estado $^{10}$, localizado na capital argentina. Jarach repudiou assim o negacionismo oficial que ainda insiste em impedir o avanço de políticas públicas de Memória, Verdade e Justiça em seus países".

10 Criado em 1998, às margens do Rio da Prata, em Buenos Aires, é um lugar de memória que conjuga a contundência de um monumento no qual estão escritos os nomes dos desaparecidos e assassinados pela ação repressiva estatal, à capacidade crítica que desperta a arte contemporânea e o contato visual com o Rio da Prata, testemunha ocular e silenciosa do destino de muitas vítimas.Ver mais em: http://parquedelamemoria.org.ar/sobre-el-parque-de-la-memoria/

I I Essas Mães argentinas foram responsáveis por um dos mais emblemáticos movimentos pelos direitos humanos contra a opressão de uma ditadura militar. De 1976-1983, essas mulheres saíram às ruas em busca de seus filhos detidos e desaparecidos. Inicialmente atuaram de forma 
Por uma política das memórias do feminino na resistência

A luta pela memória, verdade e justiça para as vítimas do Estado totalitário foi a fonte de inspiração para a frase «nunca mais o silêncio». No entanto, ao ouvi-la proferida por Jarach, uma das muitas mulheres que não silenciaram ante a repressão, ela nos despertou o desejo de falarmos sobre o apagar das memórias das mulheres nessas histórias de resistência e de reafirmarmos que a efervescência dos movimentos sociais das mulheres na contemporaneidade é memória viva em constante construção, alicerçada por um amplo conjunto de pautas que evidencia o amadurecimento e os avanços nas discussões e lutas globais feministas. Ao nosso ver, a recusa ao silêncio diz sobre todo tipo de opressão, inclusive sobre o não apagar das memórias do feminino na história de revoltas, rebeliões e resistências da humanidade. E é a partir deste ponto que a museologia, em especial a escola de pensamento do campo da sociomuseologia, tem tudo a ver com essa história.

Estamos de acordo com Aída Rechena, autora de uma tese pioneira no campo da museologia, defendida na Universidade Lusófona de Humanidades e Tecnologias - ULHT, em Portugal, na qual evoca a autonomia da sociomuseologia para adotar o gênero como "categoria analítica, relacionando-a com o património, a memória, a identidade, o território, cruzando-a com as outras categorias geradoras de desigualdades (raça/etnia, classe, idade) e os sistemas de poder, sistemas simbólicos e outros" (Rechena, 201 I: I6I).A museóloga considera que os problemas sociais enfrentados pelas mulheres no presente e as memórias coletivas construídas a partir das suas lutas por direitos constituem-se um campo de trabalho profícuo para a sociomuseologia e para os museus contemporâneos, especialmente se levarmos em conta o que nos diz Mário Moutinho (1989):"os acervos dos museus são constituídos pelos problemas das pessoas na atualidade” (Rechena, 201 I: I52-153).

No entanto, mesmo que considere as rupturas epistemológicas provocadas pela chamada Nova Museologia como propulsoras de teorias e práticas inovadoras no campo das memórias, identidades e patrimônios, e com as quais alia a sua investigação científica, na discussão de gênero, Rechena não poupa nem a própria sociomuseologia da sua análise crítica:

[...] se a sociomuseologia trabalha com questões sociais, com os problemas das minorias, com as reivindicações dos movimentos sociais, com as problemáticas relacionadas com o meio ambiente e a preservação das espécies, não tem prestado muita atenção à questão da igualdade de género, nem refletido de forma aprofundada sobre a apropriação do conceito analítico género (Rechena, 2011: 159).

Se nem a escola de pensamento da sociomuseologia escapa das fundamentadas críticas da museóloga, o que dizer da «museologia normal»? Por isso, face ao breve panorama das contribuições das mulheres às transformações sociais e políticas no mundo, apresentado neste trabalho, é inevitável que façamos algumas perguntas incômodas: onde estão essas e outras memórias de lutas e de produção social dessas mulheres? Como fazer para as atuais e futuras gerações

individual, mas logo se tornariam um movimento coletivo e, mais à frente, em instituições. A Marcha da Resistência é uma ação que acontece todos os anos. 
conhecerem e reconhecerem o poder das memórias do feminino na história da humanidade? Ainda que haja esse grande movimento mundial para a revivificação da história coletiva de lutas sociais e políticas produzida pelas mulheres, como nos diz Perrot, o que o campo da museologia tem feito para incluir essas memórias em seus processos museológicos? Esta não seria uma função social dos museus, preconizada pela recente Recomendação sobre Proteção e Promoção de Museus e Coleções, sua Diversidade e seu Papel na Sociedade da UNESCO?

\section{Panorama museal feminino - um universo em constante expansão}

Ao adentrarmos nos salões expositivos dos museus brasileiros, algumas perguntas incômodas teimam em guiar nossos pensamentos: em quais museus estão sendo contadas as histórias forjadas nas lutas das mulheres que defenderam a cidadania no tempo da colônia e da escravidão; das trabalhadoras rurais que se mobilizam pelo direito à terra e contra a destruição da nossa biodiversidade, promovida em larga escala pelo agronegócio; das mulheres indígenas líderes de movimentos pela preservação e demarcação de suas terras; das mulheres que participaram dos movimentos e organizações pelo fim da ditadura militar; das líderes dos movimentos sociais urbanos que ocupam e atuam pelo direito à moradia, contra a violência e por melhores condições de vida nas suas comunidades? Posto isto, quais museus desenvolvem uma política sistemática de inclusão das mulheres enquanto classe política e coletiva em seus processos museológicos, em seus programas, projetos e atividades? Sem muita chance de errar, arriscamo-nos a dizer que poucos, muito poucos ou, talvez, nenhum. E a resposta torna-se ainda mais pessimista quando se trata da criação de museus do feminino ou museus de mulheres, ou seja, instituições ou iniciativas de memórias cujo tema focal sejam as causas feministas. É o que veremos a seguir.

$\mathrm{Na}$ abertura do site da International Association of Women's Museums $I A W M^{12}$, uma frase da advogada, ex-juíza e ativista dos direitos humanos, Prêmio Nobel da Paz em 2003, Shirin Ebadi, nos chama a atenção: "the women are the ones who write the history of the world! There has to be a women's museum in every country of this world"' ". Apesar da concertação entre os diversos movimentos feministas do mundo em torno da ideia contida na primeira parte da frase de Ebadi, o mesmo não podemos dizer sobre a segunda. Nem mesmo no país de origem da "grande mestra da História das Mulheres», como é conhecida Michelle Perrot entre o público brasileiro, essa ideia de Ebadi tem ressonância.

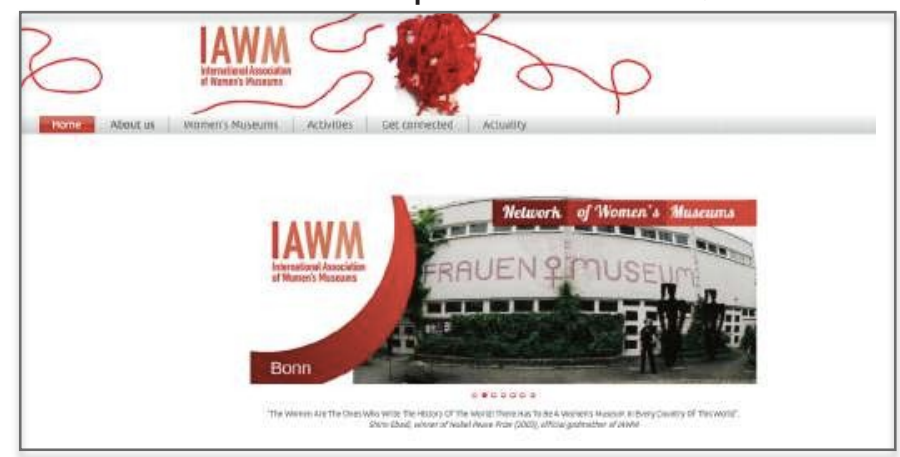

Página de abertura do site da International Association of Women's Museums - IAWM.

I2 A Associação Internacional de Museus das Mulheres foi criada em 20I2, durante o 4o Congresso Internacional da Rede de Museus da Mulher. Atualmente, a IAWM é composta por 30 museus-membros e realiza, a cada quatro anos, um congresso internacional em um continente diferente.

I3 Tradução livre: "As mulheres são as que escrevem a história do mundo! Tem que haver um museu de mulheres em todos os países deste mundo”. Frase retirada do site: http://iawm.international 
Por uma política das memórias do feminino na resistência

"O feminismo francês é um feminismo de luta que não pensou o suficiente como usar o objeto, seja uma obra de arte ou uma ferramenta diária, para uma reflexão sobre o gênero" (Lorriaux, 20I5), justifica a historiadora e antropóloga Nicole Pellegrin, pesquisadora honorária do Centre National de la Recherche Scientifique - CNRS. Esta fala de Pellegrin e o modelo de museu centrado nos objetos, quase unânime na França, talvez sejam as pistas para responder à pergunta que Aude Lorriaux faz em sua matéria jornalística, realizada em 2015: por que não temos um museu feminino na França? Mas além dessa «amarra conceitual» no campo da museologia, evidentemente existem outras questões que envolvem essa quase ausência francesa entre os 85 museus de mulheres espalhados pelo mundo, mas com forte concentração na Europa e América do Norte, conforme veremos no Gráfico I. Entre os museus computados na base de dados atualizada permanentemente pela IAWM, 17 são museus virtuais - sendo apenas um deles francês.Além disso, há ainda o registro de 35 iniciativas em curso, com o objetivo de fundar novos museus, conforme vemos no Quadro I, com dados da plataforma da IAWM, atualizados até 24/I2/2017:

Quadro I - Número de Museu de Mulheres registrados pela IAWM

\begin{tabular}{|c|r|r|r|r|r|}
\hline & $\begin{array}{r}\text { Mu- } \\
\text { seus físicos }\end{array}$ & $\begin{array}{r}\text { Mu- } \\
\text { seus vir- } \\
\text { tuais }\end{array}$ & $\begin{array}{r}\text { Total } \\
\text { Museus }\end{array}$ & $\begin{array}{r}\text { Ini- } \\
\text { ciativas em } \\
\text { processo }\end{array}$ & \\
\hline África & 04 & - & 04 & 04 & 08 \\
\hline $\begin{array}{c}\text { América } \\
\text { Central }\end{array}$ & - & 01 & 01 & 01 & 02 \\
\hline $\begin{array}{c}\text { América } \\
\text { do Norte }\end{array}$ & 27 & 05 & 32 & 01 & 33 \\
\hline $\begin{array}{c}\text { América } \\
\text { do Sul }\end{array}$ & 02 & 01 & 03 & 04 & 07 \\
\hline Ásia & 12 & 02 & 14 & 03 & 17 \\
\hline Europa & 20 & 08 & 28 & 20 & 48 \\
\hline Oceania & 03 & - & 03 & 02 & 05 \\
\hline Totais & 68 & 17 & 85 & 35 & \\
\hline
\end{tabular}

Fonte: IAWM, em 24/I2/20I7

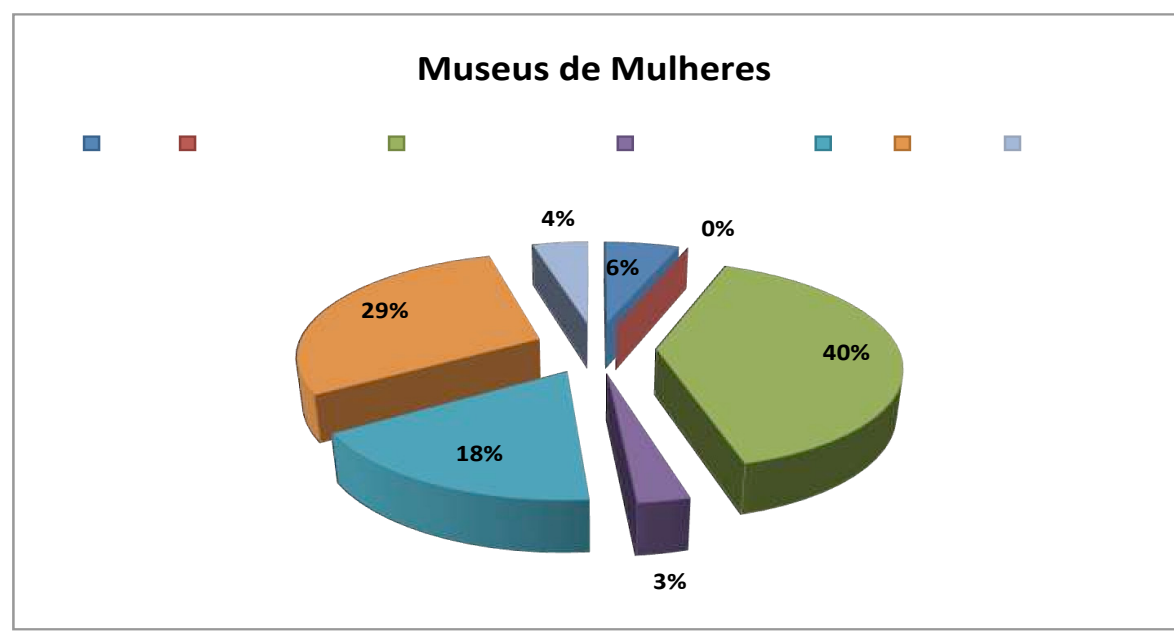

Gráfico I - Distribuição dos Museu de Mulheres registrados pela IAWM nos sete continentes. Fonte: IAWM, em 24/12/2017 
Dizemos «quase ausência francesa» porque o único museu físico existente na França e que não consta na lista do IAWM, o Musée de la Femme, é descrito como "uma antiga fazenda, na Alta Sabóia, que apresenta «a história do laço e seus diferentes pontos»..." (Lorriaux, 20I5). É evidente que esse Musée de la Femme não dá conta das histórias de resistências das mulheres francesas que, ironicamente, descobriram no cadafalso que a «igualité» anunciada pela Revolução Francesa, na verdade, não era para todos os cidadãos e cidadãs do país. Mas essa história, protagonizada por Olympe de Gouge, provavelmente não está exposta em nenhum museu francês. Nem mesmo nas 19 exposições virtuais realizadas pela Universidade de Angers para o Musea, um museu virtual criado em 2004, a partir das cinzas do projeto de um museu de mulheres proposto pela associação La Cité des Femmes, em torno de um núcleo de especialistas em história da mulher ${ }^{14}$, conforme afirmou Christine Bard, historiadora e professora de história contemporânea da Universidade de Angers e ex-presidente da associação, em entrevista a Lorriaux. Bard diz que a criação do museu nunca foi efetivada por falta de recursos financeiros, mas também de vontade política."Ao lado deste museu virtual pioneiro, e por isso 'um pouco velho', como explicado por suas criadoras, não há nenhum museu dedicado à história das mulheres e digno do nome" (Lorriaux, 20I5).

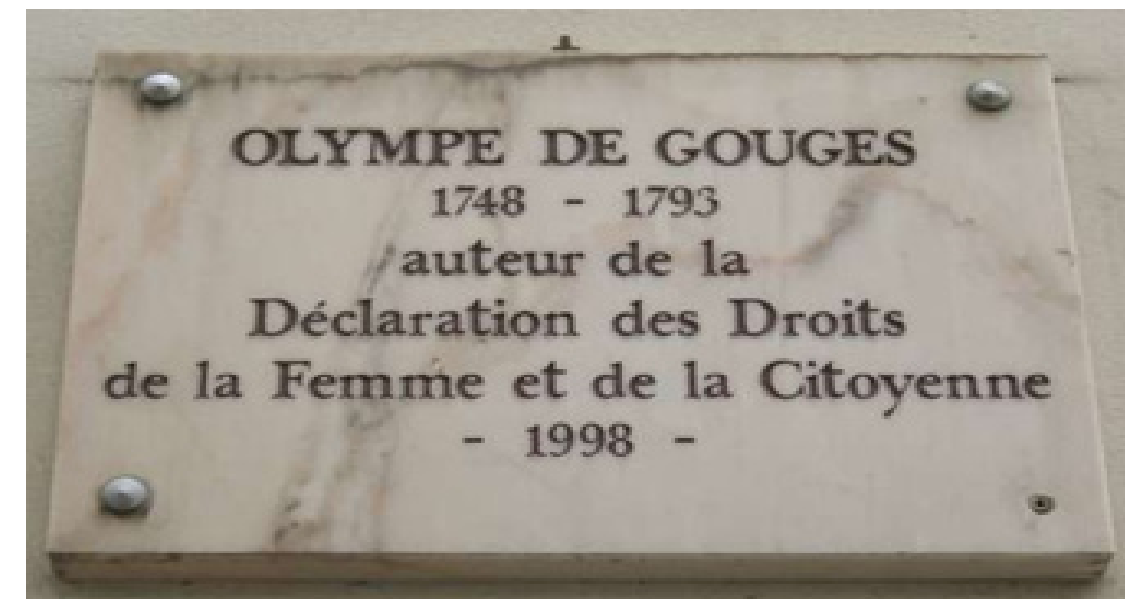

Placa afixada no $\mathrm{n}^{\circ} 20$ da Rue Servandoni, Paris $6^{\circ}$, onde residiu Olympe de Gouges ( I748-1793), autora da Declaração dos Direitos da Mulher e da Cidadã.

Fonte:Wikimedia Commons

É importante ressaltar que estamos a nos referir ao país que tem um dos maiores quantitativos mundiais de instituições museológicas, entre elas, sete estão entre as mais visitadas. Ao país que abriga a sede do Conselho Internacional de Museus - ICOM e também, no qual, foi criada a primeira experiência de ecomuseu no mundo, uma das muitas inovações propostas pela chamada Nova Museologia, o que só vem confirmar a análise crítica da museóloga portuguesa Aída Rechena, citada anteriormente.

Segundo pesquisa divulgada pela IAWM em 20I4, dos 66 museus de sua base de dados à época, mais de 40 foram criados a partir dos anos 1990. Vale salientar que $77 \%$ desses museus estão localizados na América do Norte (30) e Europa (2I). Na América do Sul, ainda que a pesquisa tenha incluído um museu

I4 A historiadora Michelle Perrot foi uma dessas especialistas que participou do conselho científico do Musea de 2004 a 2013. 
Por uma política das memórias do feminino na resistência

da Costa Rica ${ }^{15}$, podemos considerar que existem apenas dois museus da Argentina e, com base na lista atual da IAWM (2017), registra-se o MuMu Museo Virtual de la Mujer, do Chile. O Brasil não aparece na lista de museus de mulheres da IAWM, embora saibamos da existência de um único museu - o Memorial da Mulher Ceci Cunha ${ }^{16}$, criado pelo governo municipal de Arapiraca (AL) em 2008, com o objetivo de preservar "a memória das mulheres que desempenharam e desempenham um importante papel na construção da história da cidade". $\mathrm{Na}$ base de dados da IAWM consta apenas uma iniciativa para criação de um futuro museu de mulheres em Belém do Pará, no entanto, não há qualquer contato ou referência na internet.

Mas a pesquisa revelou outros dados ainda mais interessantes que corroboram com a ideia desses museus como «agentes de comunicação e de intervenção social», em sintonia com os princípios de uma museologia inclusiva e social. Segundo a IAWM (20I4), dos 66 museus inquiridos sobre a missão que fundamentava suas existências, os 40,9\% (27) que responderam ao questionário ${ }^{17}$ apresentaram as seguintes respostas:

celebrar e homenagear as mulheres, tornando visível sua história, vidas, atividades e capacidades; reconhecer, respeitar e transmitir suas experiências e contribuições;

apoiar mulheres artistas para cultivar e promover seu contributo nas artes e fornecer uma visão do mundo criativo dessas artistas;

pesquisar e compartilhar a história e a memória das mulheres, a fim de conservar e preservar seu patrimônio e transmitir a consciência de seu papel na história;

capacitar o público, adulto e infantil, a fim de transmitir conhecimento e enriquecer o entendimento da comunidade;

promover a ideia e a conscientização da igualdade de gênero, a fim de acabar com todo tipo de discriminação'18.

Também nos chama atenção o fato de que a criação de $70 \%$ desses museus foi financiada por mulheres e, às vezes, por uma única mulher. $O$ Estado responde apenas com 3\% do financiamento para a criação desse tipo de museu, o que demonstra a sua quase total inércia em relação à iniciativa de valorizar a produção social das mulheres. No entanto, a manutenção, as despesas com pessoal e a realização de eventos e atividades de $60 \%$ desses museus dependem de recursos financeiros oriundos dos poderes públicos, da iniciativa privada e da venda de ingressos. Não à toa, $63 \%$ deles apontaram a falta de recursos financeiros como um dos grandes problemas enfrentados nos últimos anos.

Uma outra questão que aproxima esses museus aos princípios de uma museologia voltada para o social é a prescindibilidade do objeto como meio

I5 Da América Central.

16 Ver em: http://memorialdamulher.blogspot.pt/p/exposicoes.html

17 Dos 27 museus pesquisados, sete eram museus virtuais, sendo: I5 da Europa, 9 da América do Norte e um da Oceania, da América Central e da Ásia, respectivamente.

18 As respostas foram reescritas, a partir da tradução livre das autoras, com o intuito de resumí-las, mas com a preocupação de tentar preservar ao máximo a essência dos seus conteúdos. 
de transmissão do conhecimento no processo museológico. A maioria desses museus (78\%) possuem uma coleção permanente, mas não necessariamente de objetos como os museus tradicionais, visto que apenas $37 \%$ dispõem de objetos próprios ou oriundos de empréstimos de longa duração. $\bigcirc$ conteúdo das coleções é variado, no entanto, refere-se de forma predominante à «História dos direitos e movimentos das mulheres» e à "Cultura de gênero» (63\%). Temas como «a vida das mulheres» e «arte feminista» também são representados nas coleções de $44 \%$ e $41 \%$ dos museus, respectivamente.

Esta pesquisa é o ponto de partida do projeto SHE Culture, financiado pelo Programa Cultura 2007-20I 3 da União Europeia, com o objetivo de promover a diversidade cultural e o diálogo intercultural e, para isso, apoia projetos que realizam a análise de políticas de gênero em áreas culturais em nível europeu e nacionais. Para o SHE Culture, os museus de mulheres são lugares estratégicos para o cumprimento desse objetivo:"eles têm a visão do observador e nos falam sobre interações entre projetos de gênero e cultura [...] que podem produzir não apenas valores sociais e culturais, mas também dar um forte contributo para a inclusão social e processos de aprendizagem ao longo da vida, bem como para a participação ativa na vida comunitária” (SHE Culture, 2017).

Com vista a atender ao objetivo geral do projeto SHE Culture, que não era estritamente museológico, mas centrado em políticas culturais orientadas para o gênero, a IAWM decidiu submeter o questionário ao universo resultante do inventário, mesmo que necessariamente essas organizações não atendessem a todos os critérios do ICOM em sua definição de museu. Para isso, incluiu em seu inventário como tendo o caráter de museu, os institutos de conservação e galerias de exposições em bibliotecas e arquivos; os monumentos e sítios naturais, arqueológicos e etnográficos e os monumentos históricos e lugares de natureza museológica, devido às suas atividades de aquisição, conservação e comunicação dos seus acervos - que, como dissemos antes, nem sempre encontram-se materializados como objetos.

A aplicação rigorosa dos critérios do ICOM revela que apenas uma porcentagem muito pequena das unidades no inventário poderia ser devidamente considerada como um museu. Em nossa opinião, isso não afeta de forma nenhuma o seu valor cultural e social, o significado de suas ações e a relevância de sua existência. (IAWM, 2014)

Esse entendimento do IAWM reforça mais ainda a necessidade do ICOM rever os seus conceitos, mas principalmente de criar novas estratégias e alianças políticas "nas quais os argumentos científicos são apenas um aspecto" (Mairresse, 2016). No campo dos museus de mulheres, por exemplo, a despeito da gestão 2016-2019 do ICOM ter 65\% dos seus cargos diretivos (Diretoria Executiva, Conselho Consultivo e Comitê Nacional ICOM) ocupados por mulheres, não há qualquer menção sobre políticas de gênero em seu Plano Estratégico 2016-2022 e, muito menos, existe um Comitê Internacional em sua estrutura que reúna esses museus. Em 2016, o Movimento para uma Nova Museologia - MINOM foi uma das poucas e, talvez, a única organização afiliada ao ICOM a incluir uma perspectiva de gênero em seus compromissos programáticos inscritos no documento Missiva de Nazaré, elaborado em sua XVII Conferência Internacional, realizada no estado de Rondônia, Brasil: "combater 
Por uma política das memórias do feminino na resistência

as diversas formas de silenciamento, apagamento e invisibilização da presença e atuação das mulheres em todos os territórios sociais, políticos e geográficos, afirmando uma perspectiva emancipatória na práxis museológica" (MINOM, 2016). Como se vê, mais uma vez foram os agentes de uma museologia de caráter social e inclusivo que tomaram a iniciativa de buscar uma política de reparação da exclusão das mulheres da história e das artes.

\section{Uma proposta reflexiva: museus de mulheres ou uma museologia com as mulheres?}

Ao fazermos esta breve comparação entre os panoramas atuais dos movimentos de mulheres, com foco nas Marchas feministas, e da incipiente rede mundial de museus de mulheres, percebemos o quanto a museologia e os museus caminham em descompasso com a História social e política produzida globalmente pelas mulheres. Boa parte dos museus no mundo continuam a perpetuar o heteropatriarcado e a enaltecer o poder das classes dominantes e se ajustam com perfeição ao perfil dos museus brasileiros, definido pelo museólogo e professor Marcelo Cunha:"representam predominantemente o segmento masculino, branco, cristão, abastado, heterossexual e com educação formal baseada em valores ocidentais tradicionais" (Cunha, 2017:84).

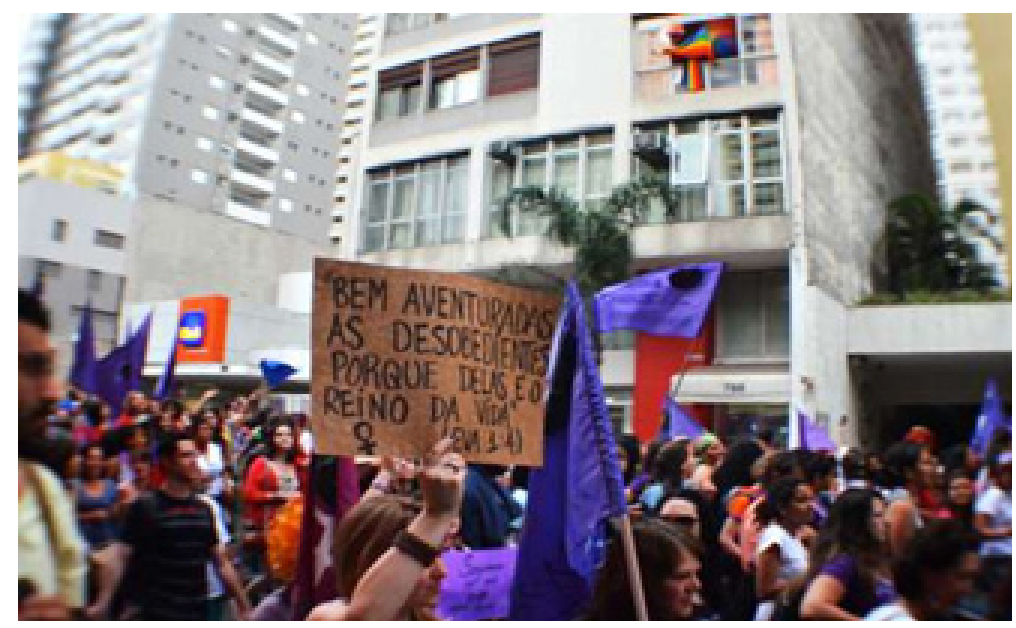

Marcha de encerramento do $9^{\circ}$ Encontro Internacional da MMM, agosto de 2013, São Paulo. Foto: Cíntia Barenho/MMM/Brasil

No entanto, sabemos que não podemos desconsiderar o debate em torno de duas questões importantes suscitadas pelas feministas francesas e das quais não devemos fugir: a possibilidade de que a criação desses museus de mulheres possa ser utilizada como desculpa para a não presença do feminino como eixo estruturante das coleções e das atividades dos museus já existentes, inclusive nas suas gestões; e o risco da «essencialização», ou seja, "de bloquear as mulheres em uma 'natureza', uma identidade fixa, em suma, uma 'essência' [...] Como se não houvesse mulheres, mas a mulher" (Lorriaux, 20I5). Defendemos, por outro lado, que esse debate não deve paralisar esse movimento pela institucionalização das memórias das mulheres e nem mesmo invisibilizar a existência desses museus mundo a fora. Eles existem e a cada dia surgem novas experiên- 
cias museais, a exigir participação nas políticas culturais dos Estados nacionais e dos organismos internacionais culturais e de museus e a assumirem um papel estratégico na produção, comunicação e compartilhamento de conhecimentos, experiências e interpretações das mulheres entre as diferentes culturas.

Temos convicção de que a existência desses museus não inviabiliza a luta por uma política de inclusão das mulheres nos processos museológicos dos demais museus, ao contrário, é um passo inicial nessa marcha feminista no campo da museologia por uma política que esteja presente nas discussões e ações de todos os museus e que aborde a questão da construção social de gênero, da sexualidade, da discriminação, da dominação ou da sub-representação institucional das mulheres.

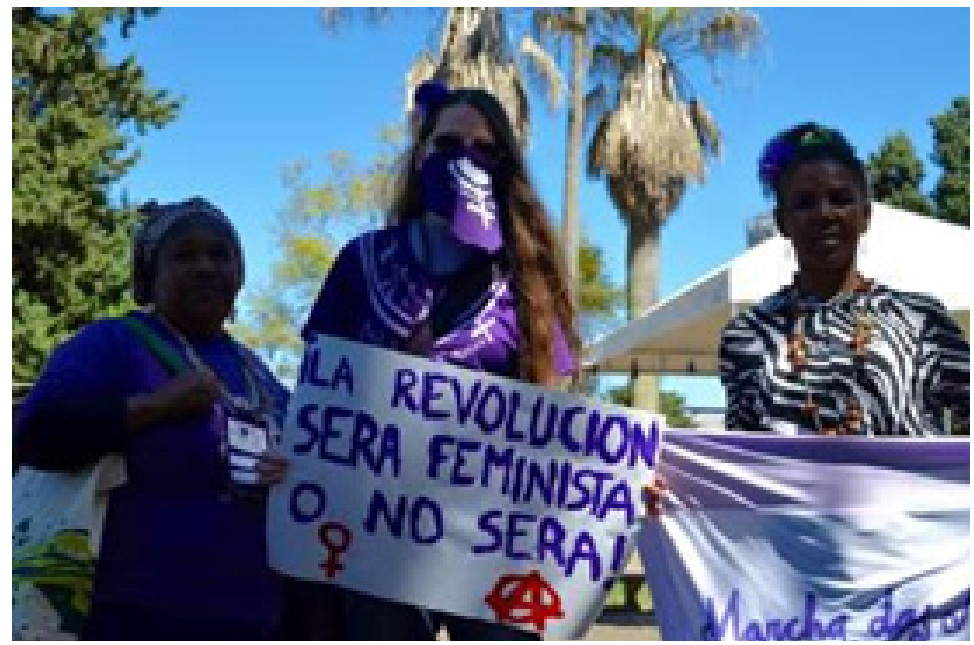

IV Ação Internacional da MMM, em Santana do Livramento (RS), reuniu mulheres brasileiras, argentinas e uruguaias, setembro/20I5. Foto:

Cintia Barenho MMM-RS/CEA

Quando dizemos política de inclusão das mulheres não estamos a nos referir a uma atividade pontual para marcar uma efeméride no calendário anual das atividades museais ou para destacar uma mulher notável em alguma área do mundo social. Estamos a tratar de uma política a ser institucionalizada pelos Estados nacionais, em caráter permanente, com programas e projetos promovidos e fomentados por instituições intranacionais, que façam a articulação entre a história produzida pelas mulheres e as instituições museais e que as mesmas incluam em seus processos museológicos, em suas pesquisas e políticas de acervos, os debates, ações e decisões em conjunto com os movimentos sociais feministas. Uma política radicalmente democrática que, efetivamente, inclua no dia-a-dia dos museus as histórias de lutas das mulheres, passadas e presentes. Uma museologia que alie-se aos movimentos das mulheres para reafirmar: «nunca mais o silêncio»». 


\section{Referências}

CONTAG, Confederação Nacional dos Trabalhadores na Agricultura. Margaridas seguem em Marcha por Desenvolvimento Sustentável com Democracia, Justiça, Autonomia, Liberdade e lgualdade - Caderno de textos para estudos e debates. Secretaria de Mulheres Trabalhadoras Rurais da CONTAG, Brasil, 2015.

CUNHA, Marcelo N. B da. Museus, Memórias e culturas afro-brasileiras. Revista do Centro de Pesquisa e Formação / No 5, p.78-88, setembro 2017.

PERROT, Michelle. Minha História das Mulheres. Tradução Angela M. S. Corrêa. São Paulo: Contexto, 2007.

PERROT, Michelle. As mulheres ou os silêncios da história. Tradução Viviane Ribeiro. Bauru, São Paulo: EDUSC, 2005.

PERROT, Michelle. Práticas da Memória Feminina In: Revista Brasileira de História,V. 9, no 18, p. 9-18. São Paulo, Ago-Set 1989.

Biroli, Flávia. O feminismo como projeto transformador: as vozes das Margaridas, In: Boitempo, publicado em 28/08/2015. Disponível em: https://blogdaboitempo.com. br/2015/08/28/o-feminismo-como-projeto-transformador-as-vozes-das-margaridas/ Acesso em 25/II/20I7

CTB - CENTRAL DOS TRABALHADORES E TRABALHADORAS DO BRASIL. I5 países da América Latina e África participam da $5^{\mathrm{a}}$ Marcha das Margaridas. Matéria publicada em II de agosto de 20I5. Disponível em: http://portalctb.org.br/site/estaduais/centro-oeste/distrito-federal//5-paises-da-america-latina-e-africa-participam-da-5-marcha-das-margaridas Acesso em: 23/1 I/2017

Davis, Angela. O discurso de Angela Davis na Marcha das Mulheres contra Trump, In: Boitempo. publicado em 23/0I/20I7 Disponível em: https://blogdaboitempo.com. br/2017/01/23/o-discurso-de-angela-davis-na-marcha-das-mulheres-contra-trump/ Acesso em 27/II/2017

IAWM - International Association of Women's Museums. Disponível em: http://iawm. international/about-us/womens-museums/museums-list/ e https://www.yumpu.com/ en/embed/view/t4II lwboJUmQM4916 Acesso em: 24/I2/2017

ICOM - INTERNATIONAL COUNCIL OF MUSEUMS. Strategic Plan 2016-2022.

Disponível em: $\quad$ http://icom.museum/fileadmin/user_upload/pdf/Strategic_Plan/ ICOM_STRATEGIC_PLAN_2016-2022_ENG.pdf Acesso em: 20/I2/2017

LORRIAUX, Aude. Pourquoi nous n'avons pas de musée des femmes en France? Publicado em 23/03/20 I5. Disponível em: http://www.slate.fr/story/99029/pourquoi-musee-femmes-france Acesso:08/12/2017

MAIRRESSE, François. The politics and poetics of Museology, call for Abstract for 40 MEMÓRIAS DA DITADURA. Instituto Vladimir Herzog. Disponível em: http://memoriasdaditadura.org.br/mulheres/index.html Acesso em: 20/I I/2017

MINOM, MOVIMENTO PARA UMA NOVA MUSEOLOGIA. Missiva de Nazaré MEMÓRIA ACESA, XVII Conferência Internacional do MINOM,Amazônia/ Brasil, 2016. Disponível em: http://www.minom-icom.net/files/minom-nazareth-3missiva-copiar.pdf 
Acesso em: 23/12/2017

MMM - MARCHA MUNDIAL DAS MULHERES. Disponível em: https://marchamulheres.wordpress.com/mmm/ Acesso em:23/l I/2017

SHE CULTURE. European Union. Disponível em: http://www.she-culture.com/en/ Acesso: em 22/12/2017

TRANSFORMATÓRIO-MM Disponível em: http://transformatoriomargaridas.org.br Acesso em: 23/II/2017 